\title{
Optimal management of intrabony defects: current insights
}

This article was published in the following Dove Medical Press journal: Clinical, Cosmetic and Investigational Dentistry

\author{
Sagrika Shukla' \\ Ashi Chug ${ }^{2}$ \\ Lanka Mahesh ${ }^{3}$ \\ Sandeep Singh ${ }^{4}$ \\ Kuldeep Singh ${ }^{5}$ \\ 'Department of Dentistry \\ (Periodontology), All India Institute \\ of Medical Sciences, Rishikesh, \\ Uttarakhand 249203, India; \\ 2Department of Dentistry, All \\ India Institute of Medical Sciences, \\ Rishikesh, Uttarakhand 249203 , \\ India; ${ }^{3}$ Private Practice, New Delhi, \\ India; ${ }^{4}$ Private Practice, Allahabad, \\ Uttar Pradesh, India; ${ }^{5}$ Department \\ of Conservative Dentistry \& \\ Endodontics, RR Dental College, \\ Udaipur, India
}

Correspondence: Sagrika Shukla Department of Dentistry (Periodontology), All India Institute of Medical Sciences, Virbhadra Road, Rishikesh 249203, Uttarakhand, India Email shukla.sagrika@gmail.com

\begin{abstract}
Periodontitis is the most common condition, which causes bony defects. Intrabony defects thought not as common as the horizontal bone loss pose a risk of disease progression and thus should be managed optimally; however, it does not mean all the intrabony defects can be treated and all the mobile teeth saved! But, with the advent of new biomaterials prognosis of teeth can be improved. The objective of this article is to discuss old and new concepts toward the optimal management of intrabony defects.
\end{abstract}

Keywords: periodontitis, bone loss, intrabony defects, bone grafting, Sticky bone ${ }^{\mathrm{TM}}$

\section{Introduction}

Periodontitis is one of the most common diseases, and the first-line treatment toward its elimination is scaling and root planing (SRP). Although literature based on clinical and systematic reviews has shown improvement in periodontal status after SRP, ${ }^{1,2}$ it also states that the therapy fails to remove pathogens from deep intrabony defects, ${ }^{3}$ leading to proliferation of infection. As a result, there are many adjuncts used along with the SRP for periodontal treatment. In a randomized control trial, Matarese et $\mathrm{al}^{4}$ studied the effects of diode laser therapy and concluded that after 1 year of treatment, there was improvement in the clinical and microbial conditions and a single session of diode laser was more effective in treating pocket depth and clinical attachment level (CAL) values, whereas microbial and inflammatory parameters were comparable to SRP alone. Other materials that can be used are antibiotics in the form of local drug delivery. However, when the combination of amoxicillin plus metronidazole was used in deep pockets, it did show effective control of pathogens, at the cost of developing antibiotic-resistant microorganisms as there was difficulty in maintaining a stable therapeutic concentration of the drug used. ${ }^{5-7}$ As a result, there is always a need to search for better biomaterials that can be used for the treatment of deep pockets. In a randomized control trial by Isola et $\mathrm{al}^{8}{ }^{8}$ new generation of desiccant liquid material, a blend of sulfonic/sulfuric acids, was used to treat chronic periodontitis. They concluded that desiccant as an adjunct to SRP showed significant results in the clinical, microbial and inflammatory parameters compared to SRP alone. But the disadvantage of such adjuncts to SRP is that, a blind procedure is being followed during their placement and the calculus still remains at the base of the pocket, also the bony defect still persists, which needs to be corrected.

Periodontitis causes attachment and underlying bone loss, creating alterations in its architecture resulting in intrabony defects of varying types. Karn et $\mathrm{al}^{9}$ in 1984 described $^{\circ}$ 
the terms moat, trench, ramp plane and crater to explain the type of intrabony defect arising from periodontal destruction of bone. Out of these, only crater is still in use, the rest of the terms have been replaced and reclassified as type I, type II and type III defects depending upon the number of walls present. ${ }^{10}$ To convert a tooth of hopeless or questionable prognosis into fair or favorable prognosis is paramount in the treatment of periodontal disease; however, periodontitis is difficult to treat, especially if the disease manifests as aggressive periodontitis. If we look at the literature, time and again, the studies by Prichard, ${ }^{11}$ Patur and Glickman, ${ }^{12}$ Wade, ${ }^{13}$ Ellegaard and Loe $^{14}$ and Seibert ${ }^{15}$ showed that bony pockets resolve by themselves if patient has good oral hygiene; however, healing largely depends upon the type of defect, three-walled defects being the most favorable. ${ }^{16}$ Thus, success and failure of grafted pockets do not only depend on the type of bone grafts used but also upon the optimal plaque control by the patient. The aforementioned statement also stands true for the treated pockets as well as the non-grafted pockets upto 5-6 mm. However, deep intrabony pockets may regenerate upto 2-3 $\mathrm{mm}$, but in authors' opinion it is unlikely for them to regenerate more than that until it has not been grafted.

The first bone graft used for periodontal regeneration was by Hegedus in $1923,{ }^{17}$ which led toward a continuous effort of production of an ideal bone graft for regeneration purposes, and xenografts became the main focus for treating periodontal disease. ${ }^{18}$ In 1936, Beube and Silvers used boiled cow bone powder for the treatment of intrabony defects. ${ }^{19}$ Forceberg in 1956 used Ox purum in 11 human intrabony defects and showed satisfactory results. ${ }^{20} \mathrm{With}$ the introduction of the Melcher concept ${ }^{21}$ in 1962, collagen membranes became widely in use, increasing the predictability of the defect prognosis. Since then, science has evolved and today we have a wide range of bone grafts from different sources, including animals, which are safe to use. ${ }^{22}$ These different bone grafts can be used as such, can also be mixed with each other or with growth factors such as platelet-rich fibrin (PRF). The aim of this study is to discuss current trends in the treatment of intrabony defects. However, periodontitis is a complex disease and even after treatment it may flare, and thus long-term oral hygiene maintenance is necessary.

\section{Periodontitis and prognosis}

Operating a pocket of $5 \mathrm{~mm}$ or more than $5 \mathrm{~mm}$ still remains a topic of discussion. Many authors believe that if a pocket of $5 \mathrm{~mm}$ is not bleeding and does not have any exudates, it can be managed through oral hygiene procedures; however, practically speaking, a pocket of $5 \mathrm{~mm}$ persists due to the lack of oral hygiene, which can anytime shift more apical requiring surgical correction, and thus if a pocket of $5 \mathrm{~mm}$ is not decreasing in depth, it can be taken up for surgical correction, keeping principal of periodontal surgery "accessibility and visibility" toward elimination of irritants into consideration. Ochsenbein's statement still stands true that pocket elimination has many facets, and considering or thinking that all the pockets can be eliminated is not necessary. ${ }^{23}$ Also, to assume that a patient with periodontal pockets, without operating or surgical correction, can be kept on a lifelong maintenance protocol would be inconsistent as periodontitis can affect at any age in either localized or generalized form and is no longer an age factor. For young patients, it becomes difficult to believe regarding their condition, unless there is tooth mobility or soft tissue loss and an intrabony defect may or may not have soft tissue loss as seen in Figures 1 and 2, where the amount of bone loss does not correspond to soft tissue loss. So, important questions to consider are prognosis and why to maintain or keep a tooth of poor prognosis in the oral cavity? To answer latter is easy or rather obvious; however, it primarily depends on the former.

As aforementioned, it is difficult to treat a deep periodontal pocket or teeth that have grade II or grade III mobility. Thus, the decision of saving periodontally compromised teeth depends upon the amount of bone loss that persists. However, these concepts were laid down many years ago. McGuire $^{24}$ in 1991 in his famous article clearly mentioned that bibliography related to prognosis after periodontal therapy was predominantly from 1950s, which is based on individual experience and are not scientific studies. Prognosis depends more upon the disease type and microbes as compared to anatomy or root proximities. ${ }^{25,26}$ Classical study by

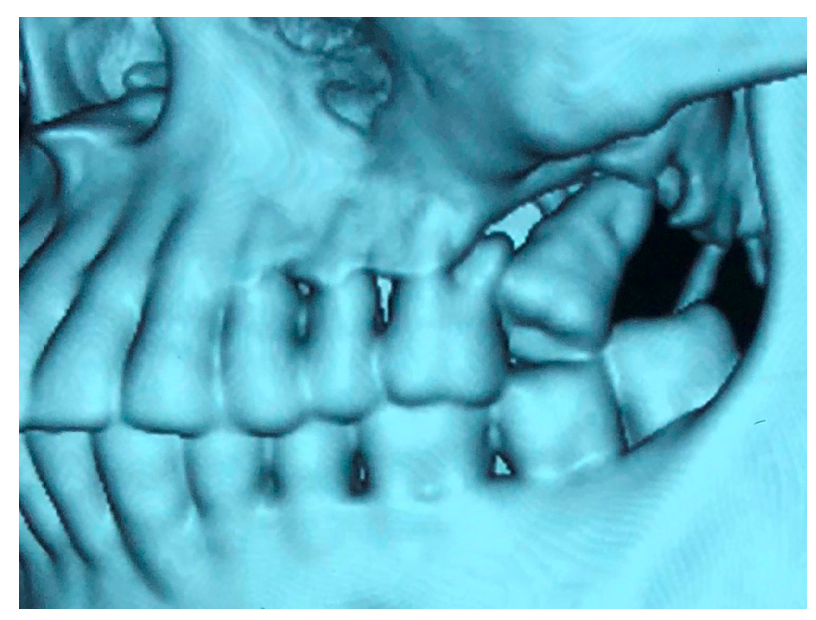

Figure I Hard tissue loss as seen on CT. Abbreviation: CT, computed tomography. 


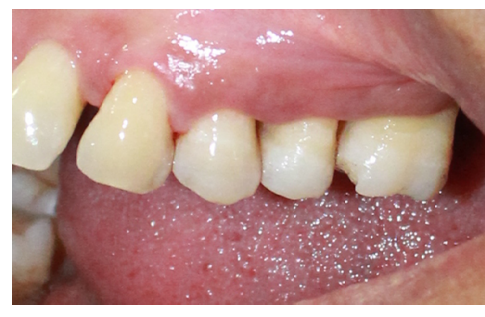

Figure 2 Soft tissue loss does not correspond to hard tissue loss.

Hirschfeld and Wasserman ${ }^{27}$ in 1986 stated that the disease follows a cyclic active pattern of cessation and exacerbation. Many treated cases responded very well for 20 years, after which there was a sudden periodontal destruction with loss of several teeth. Based on the aforementioned study, Becker et $\mathrm{al}^{28}$ stated that it is difficult to make a definitive prognosis for an individual tooth and that many teeth, which were initially labeled as hopeless, remained till 5 years. DeVore et a ${ }^{29}$ showed that it is possible to retain hopeless teeth for many years without adversely affecting adjacent teeth. So, what really affects the prognosis of teeth? In terms of intrabony defects primarily the type of defect. Three-walled defects have good results, but teeth with two-walled and one-walled defects represent with poor prognosis; ${ }^{30}$ however, these can be converted to good to fair prognosis, where the treatment of choice is bone grafting.

\section{Role of bone grafts}

Among bone grafts, autogenous bone is considered as the gold standard; however, it has a high absorption rate, thus for the treatment of generalized chronic periodontitis, a biomaterial with slow resorption should be considered such as xenografts or two or more different types of grafts can be mixed together such as xenograft with or without autogenous bone or allografts. Unfortunately, systematic reviews performed by Trombelli et $\mathrm{al}^{31}$ and Reynolds et $\mathrm{al}^{32}$ do not show complete agreement in the use of bone grafts for the treatment of intrabony pockets as the inclusion criteria were not similar and there is insufficient evidence to support the clinical use of bone replacement graft materials in intrabony defects due to significant heterogeneity among included studies. When huge defects are to be grafted, barrier membranes are used to improve the prognosis of the grafted site. In a more recent study, a review by Cortellini and Tonetti ${ }^{33}$ published in 2015, it was clearly stated that various studies report increased CAL gain and probing pocket-depth (PPD) reduction when barrier membranes were used in the treatment of intrabony defects. Bone grafts can also be used with growth factors such as platelet-rich plasma (PRP) ${ }^{34}$ or PRF, and Sticky bone ${ }^{\mathrm{TM}}$ or Sticky gel ${ }^{\mathrm{TM}}$ can be procured $^{35}$ (Figures 3 and 4). The basic difference in both the biomaterials is that former is based on the concept of Sohn et $\mathrm{al}^{35}$, and latter is made with A-PRF plus bone graft material developed by $\mathrm{Dr}$ Choukroun. PRFs such as i-PRF and A-PRF have shown better results as compared to PRP. ${ }^{36}$ Both these biomaterials are based on low speed centrifugation concept (LSCC), and along with growth factors also provide macrophages that help in the sustainability of PRF for a period of 7-28 days. ${ }^{37}$ Thus, the advantage of using sticky bone is that the graft becomes embedded in the matrix of PRF, which along with a bone graft material provides surges of growth factors, improving healing and initiating soft and hard tissue regeneration, and it can be molded or cut into desired shape and can be packed

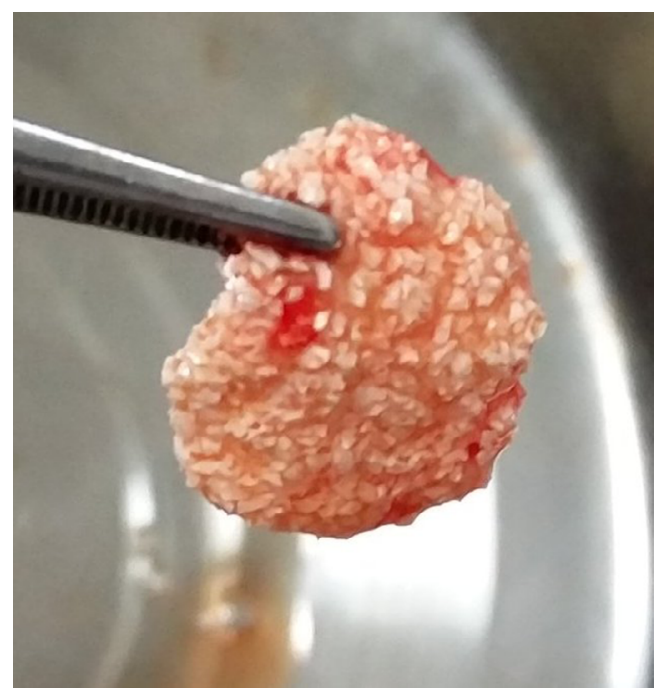

Figure 3 Sticky bone ${ }^{T M}$.

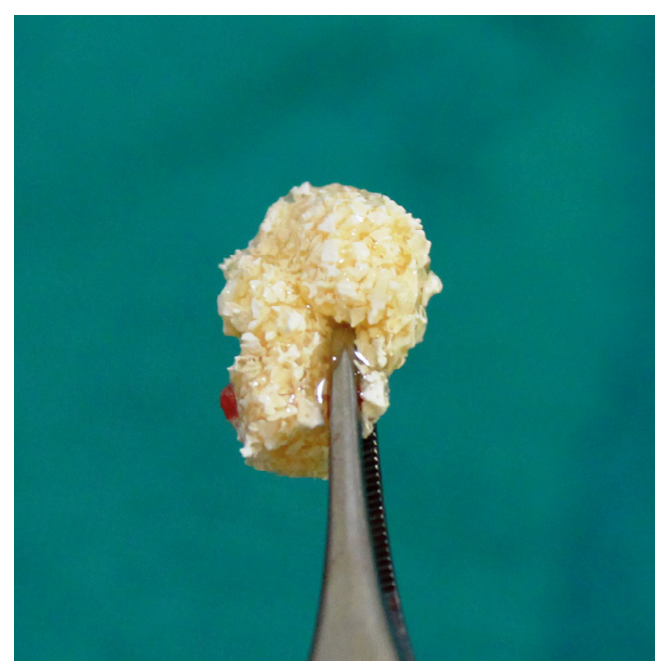

Figure 4 Sticky gel ${ }^{\mathrm{TM}}$. 
easily at the site required. This coagulum of bone graft + liquid PRF can be prepared with any bone graft material. However, a xenograft should be preferred, as it has slow resorption rate that acts well in cessations and exacerbation periods of periodontal surgery, and injectable platelet rich fibrin/advanced platelet rich fibrin (i-PRF/A-PRF) provides growth factors, improving the prognosis. In recent systematic review and meta-analysis by Panda et $\mathrm{al}^{38}$ on effectiveness of PRP combined with bone grafts in intrabony defects, the authors concluded that PRP is overall beneficial when used as an adjunct with other regenerative surgical procedures, but not in combination with guided tissue regeneration (GTR). Interestingly, the same study also concluded a meta-analysis, which showed a significant benefit only for PRF and not for PRP.

\section{Is surgery the only solution?}

In routine practice, oral prophylaxis or nonsurgical periodontal therapy is the first-line treatment, even if deep pockets persist. This reduces pocket depth and inflammation upto some extent. Nonactive periodontitis or pocket depth of upto 4-5 mm can be treated with oral prophylaxis along with systematic antibiotics or local drug delivery. In patients who cannot afford surgical therapy, this line of treatment can be used as a maintenance therapy along with proper self-care. ${ }^{39}$ However, as aforementioned, prognosis of teeth presenting with periodontitis is difficult to establish. Patients in whom residual pocket depth persists, which does not respond to nonsurgical therapy, it leads to tooth loss. ${ }^{40,41}$ Graziani et al ${ }^{42,43}$ concluded that not only a pocket depth of $\geq 6 \mathrm{~mm}$ will lead to progression of the disease and tooth loss eventually, but a pocket depth of $\geq 5 \mathrm{~mm}$ is also associated with tooth loss in the long term. They also suggested that periodontal surgery benefits the patient in terms of pocket reduction and microbial shift, especially in cases of intrabony defects and furcation involvement. Thus, in authors' opinion a pocket of $\geq 5 \mathrm{~mm}$ if not responding after 1 month of Phase I therapy, it should be taken up for surgical treatment. In an unpublished data by the authors, it was observed that a pocket of $5 \mathrm{~mm}$ did not respond after oral prophylaxis and placement of Coenzyme Q10 and affected site had to be grafted with bone graft + A-PRF after a period of 6 months of follow-up. In cases of intrabony defects or furcation involvement, if after Phase I therapy, periodontal attachment has been resolved in spite of radiographically evident bony defect, then such defects should be taken up for the surgery along with bone grafting as slight lapse in plaque control by the patient can lead to disease progression.
In majority of cases when a patient visits the dental office, there is soft tissue loss at multiple places, but results of the therapy are excellent where there is no soft tissue loss in teeth with periodontal bony defects, as the soft tissue becomes sort of a cup or a pouch, where graft along with the membrane can be placed successfully as it holds the graft in place. So, what sort of cases should be grafted? In the literature, there is emphasis regarding the treatment of intrabony defects, which states that such defects should be grafted (Figures 5-8), but very less attention has been paid to horizontal bone loss. This is so because data indicate that, if untreated, vertical defects are more prone to disease progression than horizontal bone loss. ${ }^{43}$ In contrast, Greenstein et $\mathrm{al}^{44}$ stated that angular defects do not make a site more prone to further breakdown as compared to horizontal defects in well-maintained patients. However, horizontal bone loss usually persists with soft tissue loss (Figure 9), making the sites difficult to graft. In such cases, the only option left is to keep the patient on maintenance phase or place implants. Nonetheless, if the site with horizontal bone

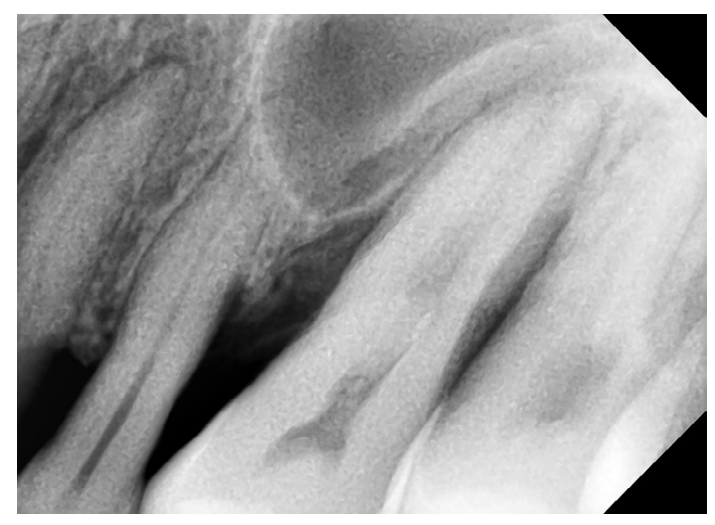

Figure 5 Pre-operative bone loss as seen in IOPA irt 24, 25, and 26. Abbreviations: IOPA, intraoral periapical radiograph; irt, in relation to.

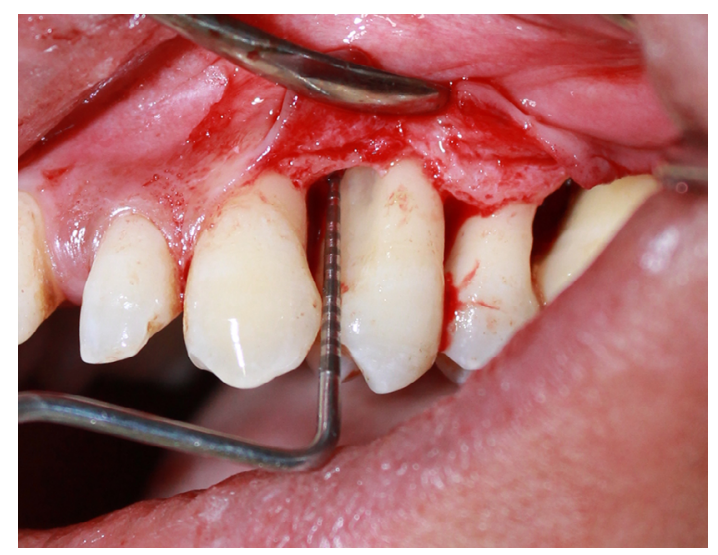

Figure 6 Vertical defects after complete debridement. 


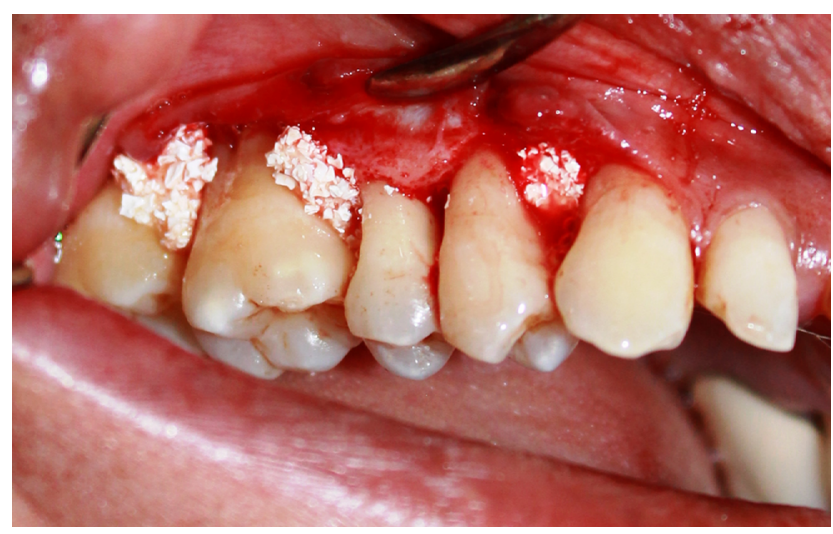

Figure 7 Placement of Sticky gel ${ }^{\mathrm{TM}}$ irt 24, 25, 26, and 27. Abbreviation: irt, in relation to.

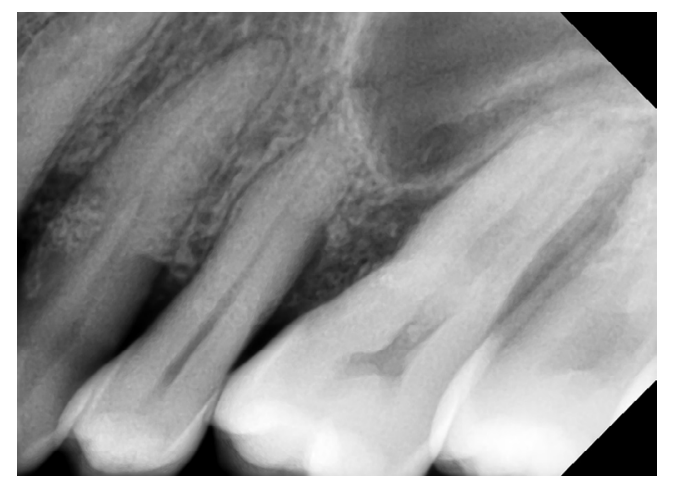

Figure 8 Post-operative IOPA at 4 months shows healing of vertical defects in progress.

Abbreviation: IOPA, intraoral periapical radiograph.

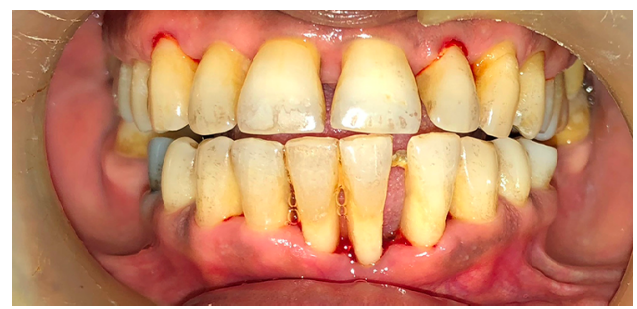

Figure 9 Hard and soft tissue loss in horizontal bony defects.

loss is well covered with soft tissue and provides scope for bone grafting, it should be treated so (Figures 10-12). With the advent of bone grafts + A-PRF, bone grafting in horizontal bone loss cannot be taken as a contraindication anymore. Grafting of such sites has become easy since the graft is in a form of condensed mass, and its placement even in a nonintrabony defect becomes effortless. As far as combined perio-endo lesions are concerned, root canal treatment before commencing periodontal surgery becomes

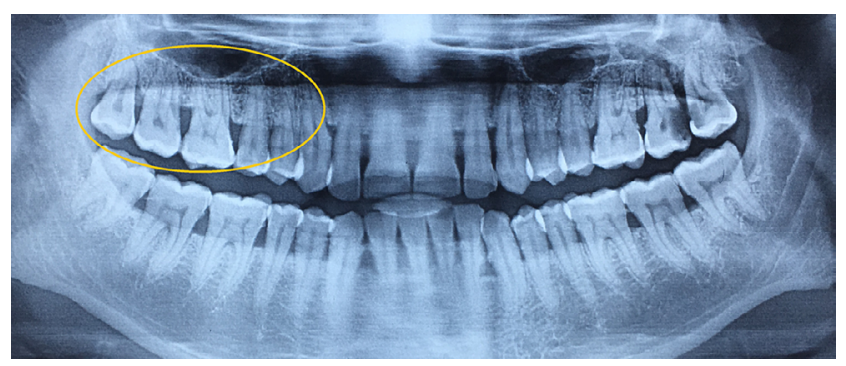

Figure 10 Horizontal bony defects.

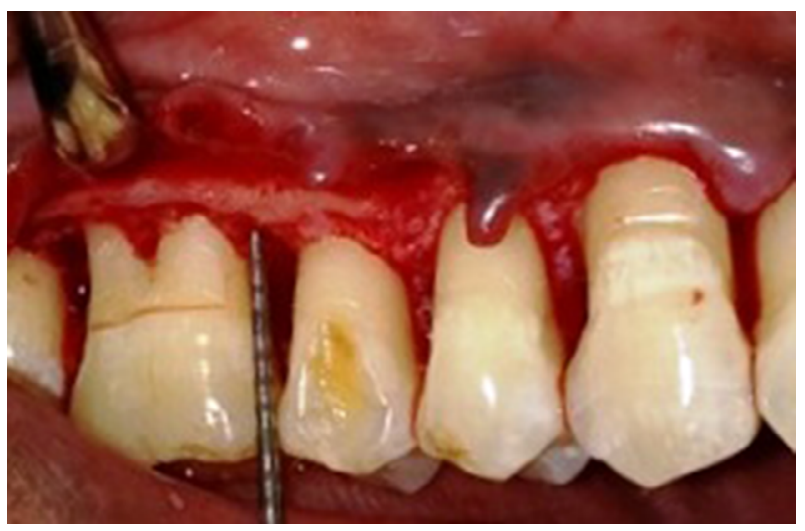

Figure I I Horizontal bony defects after complete debridement.

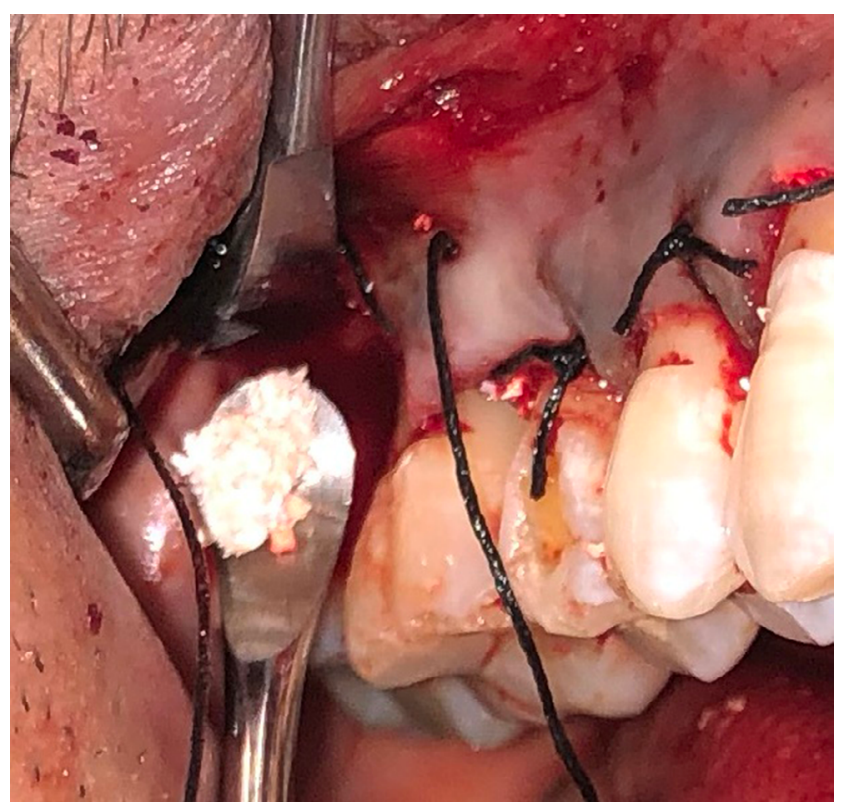

Figure 12 Placement of Sticky gel ${ }^{\mathrm{TM}}$.

paramount. However, the challenge faced in such cases is the calcified canals ${ }^{45}$ (Figure 13), resulting in poor prognosis. Nonetheless, root canal treatment should be done before 


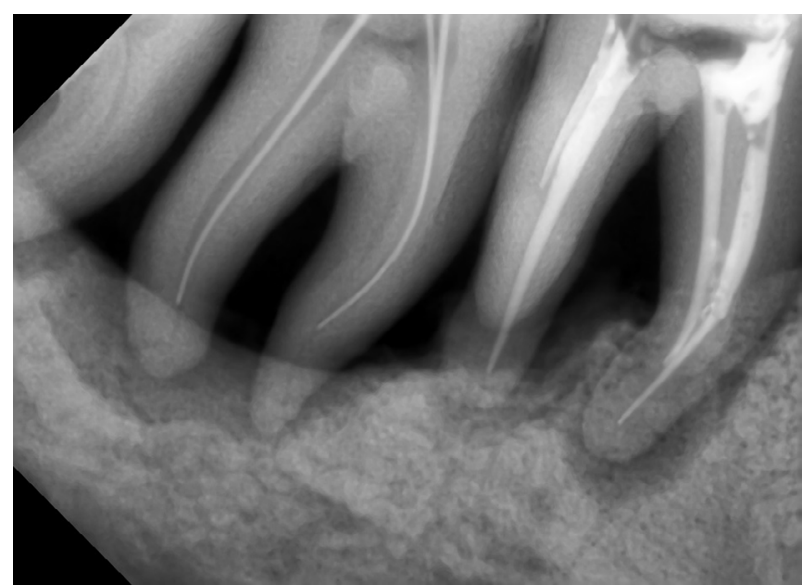

Figure 13 Calcified canals in relation to obturated 36 and undergoing RCT of 37. Abbreviation: RCT, root canal treatment.

periodontal surgery. If teeth with large defects have grade II mobility, before and after grafting, teeth should be splinted. Splinting of teeth is a prime factor that many of us forget. It has been stated in the literature that bone is capable of fully regenerating itself, provided the new bone formed has adequate blood supply, for which stabilization of the grafted site is necessary. ${ }^{46}$ This gives clinicians more reasons to use bone graft + A-PRF, which via growth factors aid in neovascularization and the stability that they provide due to platelet agglutination. Treatment of grade III mobile teeth still remains a topic of discussion, and in authors' opinion, it can be treated provided there is no soft tissue loss.

Few basic rules to be considered before any periodontal surgery are the systemic health of the patient and common conditions such as diabetes and blood pressure should be within normal limits. As far as smoking is concerned, periodontal surgery is never a motivation for smokers to quit their habit, such patients can be asked to reduce number of cigarettes or quit for a period of 3-4 weeks, which sometimes becomes impossible for chronic smokers. Economically, a periodontal surgery along with bone grafting is more cost relevant as compared to full mouth rehabilitation with dental implants. Also, biologic complications related to implants such as loss of natural dentition, malpositioning while its placement, pockets related to implants, bone loss around an implant and implant failure are much difficult to treat as compared to pockets and bone loss occurring in natural dentition. ${ }^{46}$ Hence, long-term maintenance of teeth through periodontal surgery (when possible) remains important.

\section{Conclusion}

The aforementioned literature shows that periodontitis is an unpredictable disease, which can flare up even after the treatment and that there is no way by which the stability of grafted pocket can be analyzed and predicted..$^{43}$ Yet, the treatment provides relief and improves quality of life of the patient. After surgical therapy, mobility improves, pain or exudates from the pocket stops and patient is able to chew again, which was becoming difficult due to the disease. Yet, while treating such patients with deep bony defects, there are few points that must be kept in mind, and in conclusion, clinicians can only rely on the following current clinical insights toward the treatment of periodontitis. 1) A pocket of $\geq 5 \mathrm{~mm}$ should be operated upon along with or without bone grafting. 2) Bone graft + A-PRF is the material of choice when bone grafting is performed. 3) Material preferred for preparing bone graft + A-PRF is a xenograft. 4) Grafting can also be performed in horizontal bone defects, as long as they can be grafted. 5) Root canal treatment is paramount before treating combined perio-endo lesions. 6) Pocket elimination should be carried out before root coverage procedures. 7) Prognosis becomes good when there is no soft tissue loss. 8) Mobile teeth should be splinted before and till 6 months after bone grafting procedures.

\section{Disclosure}

The authors report no conflicts of interest in this work.

\section{References}

1. Tunkel J, Heinecke A, Flemmig TF. A systematic review of efficacy of machine-driven and manual subgingival debridement in the treatment of chronic periodontitis. J Clin Periodontol. 2002;29(3):72-81.

2. Teughels W, Dhondt R, Dekeyser C, Quirynen M. Treatment of aggressive periodontitis. Periodontol 2000. 2014;65(1):107-133.

3. Oda S, Nitta H, Setoguchi T, Izumi Y, Ishikawa I. Current concepts and advances in manual and power-driven instrumentation. Periodontol 2000. 2004;36(36):45-58.

4. Matarese G, Ramaglia L, Cicciù M, Cordasco G, Isola G. The effects of diode laser therapy as an adjunct to scaling and root planing in the treatment of aggressive periodontitis: a 1-year randomized controlled clinical trial. Photomed Laser Surg. 2017;35(12):702-709.

5. Sgolastra F, Gatto R, Petrucci A, Monaco A. Effectiveness of systemic amoxicillin/metronidazole as adjunctive therapy to scaling and root planing in the treatment of chronic periodontitis: a systematic review and meta-analysis. J Periodontol. 2012;83(10):1257-1269.

6. Smiley CJ, Tracy SL, Abt E, et al. Systematic review and meta-analysis on the nonsurgical treatment of chronic periodontitis by means of scaling and root planing with or without adjuncts. $J$ Am Dent Assoc. 2015;146(7):508-524.

7. Haffajee AD, Socransky SS. Microbial etiological agents of destructive periodontal diseases. Periodontol 2000. 1994;5(5):78-111.

8. Isola G, Matarese G, Williams RC, et al. The effects of a desiccant agent in the treatment of chronic periodontitis: a randomized, controlled clinical trial. Clin Oral Investig. 2018;22(2):791-800.

9. Karn KW, Shockett HP, Moffitt WC, Gray JL. Topographic classification of deformities of the alveolar process. J Periodontol. 1984;55(6):336-340.

10. Newman GM, Takei HH, Carranza FA. Carranza's Clinical Periodontology. 9th ed. Philadelphia: W.B. Saunders Company; 2002.

11. Prichard J. The Infrabony technique as a predictable procedure. J Periodontol. 1957;28(3):202-216. 
12. Patur B, Glickman I. Clinical and roentgenographic evaluation of the post treatment healing of infrabony pockets. J Periodontol. 1962;33(2):164-171.

13. Wade AB. The flap operation. J Periodontol. 1966;37(2):95-99.

14. Ellegaard B, Löe H. New attachment of periodontal tissues after treatment of intrabony lesions. J Periodontol. 1971;42(10):648-652.

15. Seibert JS. 1973 Surgical management of osseous defects. In: Goldman HM, Cohen DW. editors. Periodontal Therapy. Saint Louis: C. V. Mosby; 789-790.

16. Polson AM, Heijl LC. Osseous repair in infrabony periodontal defects. J Clin Periodontol. 1978;5(1):13-23.

17. Hegdus $Z$. The rebuilding of the alveolar process by bone transplantation. Dent Cosmos. 1923;65:736-742.

18. Mahesh J, Mahesh R, John J. Predictability of bone regeneration in periodontal surgery. a review. J Dent Med Sci. 2012;2:46-50.

19. Beube FE, Silvers HF. Further studies on bone generation with the use of boiled heterogeneous bone. J Periodontol. 1936;7(1):17-21.

21. Melcher AH, Dent HD. The use of heterogenous anorganic bone as an implant material in oral procedures. Oral Surg Oral Med Oral Pathol. 1962;15:996-1000.

22. Rita Singh R, Mahesh L, Shukla S, Mahesh L. Infections resulting from bone grafting biomaterials. International Journal of Oral Implantology \& Clinical Research. 2013;4:68-71.

23. Ochsenbein C. Current status of osseous surgery. J Periodontol. 1977;48(9):577-586.

24. McGuire MK. Prognosis versus actual outcome: a long-term survey of 100 treated periodontal patients under maintenance care. J Periodontol. 1991;62(1):51-58.

25. Haffajee AD, Socransky SS, Goodson JM. Clinical parameters as predictors of destructive periodontal disease activity. J Clin Periodontol. 1983;10(3):257-265.

26. Haffajee AD, Socransky SS. Attachment level changes in destructive periodontal diseases. J Clin Periodontol. 1986;13(5):461-472.

27. Hirschfeld L, Wasserman B. A long-term survey of tooth loss in 600 treated periodontal patients. J Periodontol. 1986;13:461-472.

28. Becker W, Becker BE, Berg LE. Periodontal treatment without maintenance. A retrospective study in 44 patients. J Periodontol. 1984;55(9):505-509.

29. DeVore CH, Beck FM, Horton JE. Retained "hopeless" teeth. Effects on the proximal periodontium of adjacent teeth. J Periodontol. 1988;59(10):647-651.

30. Sharma A, Pradeep AR. Treatment of 3-wall intrabony defects in patients with chronic periodontitis with autologous platelet-rich fibrin: a randomized controlled clinical trial. J Periodontol. 2011;82(12):1705-1712.

30. Trombelli L, Heitz-Mayfield LJ, Needleman I, Moles D, Scabbia A. A systematic review of graft materials and biological agents for periodontal intraosseous defects. J Clin Periodontol. 2002;29(3):117-135.

32. Reynolds MA, Aichelmann-Reidy ME, Branch-Mays GL, Gunsolley JC. The efficacy of bone replacement grafts in the treatment of periodontal osseous defects. A systematic review. Ann Periodontol. 2003;8(1):227-265.
33. Cortellini P, Tonetti MS. Clinical concepts for regenerative therapy in intrabony defects. Periodontol 2000. 2015;68(1):282-307.

34. Shukla S, Chug A, Mahesh L, Grover HS. Effect of addition of platelet-rich plasma to calcium phosphosilicate putty on healing at 9 months in periodontal intrabony defects. J Contemp Dent Pract. 2016;17(3):230-234.

35. Sohn DS, Huang B, Kim J, Park WE, Park CC. Utilization of autologous concentrated growth factors (CGF) enriched bone graft matrix (Sticky Bone) and CGF-enriched fibrin membrane in implant dentistry. $J$ Implant Adv Clin Dent. 2015;7:11-28.

36. Choukroun J, Ghanaati S. Reduction of relative centrifugation force within injectable platelet-rich-fibrin (PRF) concentrates advances patients' own inflammatory cells, platelets and growth factors: the first introduction to the low speed centrifugation concept. Eur J Trauma Emerg Surg. 2018;44(1):87-95.

37. Martinez FO, Helming L, Gordon S. Alternative activation of macrophages: an immunologic functional perspective. Annu Rev Immunol. 2009;27:451-483.

38. Panda S, Doraiswamy J, Malaiappan S, Varghese SS, Del Fabbro M, del M. Additive effect of autologous platelet concentrates in treatment of intrabony defects: a systematic review and meta-analysis. J Investig Clin Dent. 2016;7(1):13-26.

39. Slots J. Low-cost periodontal therapy. Periodontol 2000. 2012;60(1):110-137.

40. Heitz-Mayfield LJ, Lang NP. Surgical and nonsurgical periodontal therapy. Learned and unlearned concepts. Periodontol 2000. 2013;62(1):218-231.

41. Matuliene G, Pjetursson BE, Salvi GE, et al. Influence of residual pockets on progression of periodontitis and tooth loss: results after 11 years of maintenance. J Clin Periodontol. 2008;35(8):685-695.

42. Graziani F, Karapetsa D, Mardas N, Leow N, Donos N. Surgical treatment of the residual periodontal pocket. Periodontol 2000. 2018;76(1):150-163.

43. Papapanou PN, Wennström JL. The angular bony defect as indicator of further alveolar bone loss. J Clin Periodontol. 1991;18(5): $317-322$.

44. Greenstein B, Frantz B, Desai R, Proskin H, Campbell J, Caton J. Stability of treated angular and horizontal bony defects: a retrospective radiographic evaluation in a private periodontal practice. J Periodontol. 2009;80(2):228-233.

45. Sunitha VR, Emmadi P, Namasivayam A, Thyegarajan R, Rajaraman V. The periodontal - endodontic continuum: a review. J Conser Dent. 2008;11:54-62.

46. Newman GM, Takei HH, Klokkevold P, Carranza FA. Carranza's Clinical Periodontology. 12th ed. Philadelphia: W.B. Saunders Company; 2014.

47. Donos N, Laurell L, Mardas N. Hierarchical decisions on teeth vs. implants in the periodontitis-susceptible patient: the modern dilemma. Periodontol 2000. 2012;59(1):89-110.
Clinical, Cosmetic and Investigational Dentistry

\section{Publish your work in this journal}

Clinical, Cosmetic and Investigational Dentistry is an international peer-reviewed, open access, online journal focusing on the latest clinical and experimental research in dentistry with specific emphasis on cosmetic interventions. Innovative developments in dental materials, techniques and devices that improve outcomes and patient satisfac-

\section{Dovepress}

tion and preference will be highlighted. The manuscript management system is completely online and includes a very quick and fair peerreview system, which is all easy to use. Visit http://www.dovepress com/testimonials.php to read real quotes from published authors. 